\title{
A Study of the Diode Laser Phototherapy for Enhancing Healing and Reduction of Microbial Count in Periodontal Pockets within a Saudi Community
}

\author{
${ }^{1}$ Mahitab Mahmoud M. Soliman, ${ }^{2}$ Sherifa Mostafa M. Sabra, ${ }^{3}$ Ammar Saleh \\ Al-Shammrani and ${ }^{4}$ Abd El-Latif A. Sorour \\ ${ }^{I}$ (Const. Oral Surgery, Prof. Oral and Maxillofacial Surgery, College of Dentistry) \\ ${ }^{* 2}$ (Const. Microbiology, Asst. Prof., Micro. Br., Biology Dept., Science College) \\ ${ }^{3}$ (Const. Restorative and Esthetic Dentistry, Ass. Prof. Conservative Dentistry, College of Dentistry) \\ and \\ ${ }^{4}$ (Const. Biotechnology, Prof. Deanship of Scientific Research) \\ 1, ${ }^{2}, 3 \& 4$ (Taif University, KSA)
}

\begin{abstract}
This research was carried out to assess Diode Laser(DL)therapeutic effects on chronic periodontitis, by reducing pockets depth and minimizing Microbial Counts (MCs). Patients(Pts)under study were 50Pts, they had chronic pockets periodontitis of more than $5 \mathrm{~mm}$ depth, were divided into 35Pts study group(SG) and 15Pts control group $(C G)$. All Pts were subjected to scaling, SG received DL therapy, $C G$ received same treatment but instead of DL therapy irrigation with normal saline. The operation period (10weeks) were divided into: phase I (baseline) at 1st week, phase 2 (treatment sessions) at 2nd, 4th, and 6th week, and phase3 (follow up) at 10th week. Clinical parameters evaluation and MCs were detected during the operation period. Index of Bleeding on Probing (BOP) had been improved greatly in SG as 96.9\%, while CG 20.5\%. Plaque Index (PI), and Pocket Depths (PD), were more reduced in SG than CG. Colony Forming Units $/ \mathrm{ml}$ (CFUs/ml) were reduced with DL therapy which revealed (400,320,250, 170 and 90) and (410,350,300, 260 and 190) for SG and CG respectively, that were confirmed $S G$ were significantly better than CG. DL irradiation revealed anti-microbial effect and reduction of inflammation in periodontal pockets, also, combination with scaling, supports healing of periodontal pockets through microbial eliminating.
\end{abstract}

Key words: Diode Laser(DL), Chronic periodontitis, Microbial Counts(MCs), Patients(Pts), Periodontal Pockets, Probing Depth (PD), Plaque Index (PI), Bleeding on Probing (BOP), Colony Forming Units/ml (CFUs/ml).

\section{Introduction}

Periodontitis is a microbial related inflammatory disease causing destruction of tooth supporting tissues namely periodontal ligament and alveolar bone. Non- surgical treatment of such destructive disease was based on the elimination of bacterial deposits adhered to tooth surfaces, primarily by means of root scaling and planning. This method, together with dental plaque control performed by the patient, is efficient in the treatment of periodontal diseases ${ }^{[1]}$. Since it is known that periodontal disease is a chronic inflammatory disease caused by a bacterial infection, hence the bactericidal and detoxifying effect of laser treatment is advantageous in periodontal therapy ${ }^{[2]}$. DL has bactericidal effectiveness ${ }^{[3]}$ Moreover, there is a significant suppression of Actinomycete mcomitans, an invasive bacterium that is associated with aggressive forms of periodontal disease that are not readily treated with conventional scaling and root planning (SRP). Actinomycete mcomitans is not only present on the diseased root surface, but it also invades the adjacent soft tissues, making it difficult to be removed by mechanical periodontal instrument alone ${ }^{[4]}$. DL provides a non-antibiotic solution. Actinomycete mucomitans has also been found in atherosclerotic plaques ${ }^{[5]}$ and there has been evidence to suggest that subgingival Actinomycete mucomitans may be related to coronary heart disease ${ }^{[6]}$. This makes it even more compelling to seek methods to control this aggressive pathogen. DLs are very effective for soft tissue applications including incision, hemostasis and coagulation ${ }^{[7]}$. Many advantages of DL, over the scalpel blade have been discussed in the literature. These include a bloodless operating field, minimal swelling and scarring, and much less or no postsurgical pain. When DL surgical procedures are carried out, the surface produced heals favorably as an open wound, without need for sutures or surgical dressings ${ }^{[8]}$. Most conventional methods used to treat the disease involve disruption of the biofilm by mechanical removal of sub-gingival plaque and, sometimes, the adjuvant use of anti-microbial agents and mechanical surgical debridement of pocket and root surfaces damaged as a result of periodontal disease. An alternative (ecological) approach would be to get rid of the putative pathogens ${ }^{[9]}$. Non-surgical therapy leads to resolution of inflammation, reduction of bacterial load, and reduction in probing pocket depth. However, the complete removal of bacterial toxins from the root 
surfaces, in deep periodontal pockets is not always achieved with non-surgical therapy ${ }^{[10]}$. .Instrumentation is not possible in inaccessible areas such as bifurcation, grooves, and concavities ${ }^{[11]}$. Also, sonic and ultrasonic instrumentation does not lead to killing of peri-pathogens ${ }^{[12]}$. These instruments help to reduce the bacterial load by mechanical removal of plaque and calculus. Thus, surgical therapy performed in cases with persistent inflammation, deeper pockets, class II and III bifurcation defects, and intra-bony defects provides better accessibility to root surfaces as well as osseous defects. However, peri-pathogens persist in the mixed-species plaque biofilm on tooth surfaces, adhere to and enter the epithelial cells, and are tissue invasive in nature ${ }^{[13]}$. These are sources for re-colonization and reinfection. The limitations of the conventional therapy have probed us to implement the use of adjunctive antimicrobial measures. Laser-assisted periodontal therapy has attracted attention recently as a potential alternative or adjunct to conventional mechanical debridement ${ }^{[14]}$. $\mathrm{CO}_{2}$ laser, Neodymium-doped: Yttrium-Aluminum-Garnet (Nd:YAG) Laser, and DL and Erbium-doped:YttriumAluminium-Garnet (Er:YAG) Laser have A part of Laser energy scatters and penetrates during irradiation into periodontal pockets. The attenuated Laser at a low energy level might then stimulate the cells of surrounding tissue resulting in reduction of inflammatory conditions in cell proliferation, increased flow of lymph improving the periodontal tissue attachment and possibly reducing postoperative pain ${ }^{[16]}$. DL has a wave length of $810 \mathrm{~nm}$ or (910-980nm), which does not interact with dental hard tissues. Therefore, DL is an excellent soft tissue surgical Laser, indicated for cutting and coagulating gingiva and oral mucosa, and for soft tissue curettage or secular debridement. It also has a bactericidal effect ${ }^{[17]}$. During last years, numerous research groups verified the lethal effect of DL radiation on microorganisms associated with dental caries, periodontitis and periimplantitis ${ }^{[18]}$.

The aim: Examination of DL therapeutic effect as recent irradiation treatment through clinical dental parameters, examine the effects of DL in reducing microbial counts, and follow up healing processes during operation period on chronic periodontitis.

\section{Materials and Methods}

Research group: This study was conducted at the dental clinic out-patient of Taif University Girls' Section at 2014. A total number of 50pts. with chronic periodontitis were selected. Their ages ranged from (22-47yrs.) with average 34.5yrs. All Pts. received non-surgical periodontal treatment, after which the involved teeth were designated to either study or control groups. Both groups received scaling, root planning and coronal polishing (SRP) and patients assigned to the test group received both (SRP+DL). Inclusion criteria: patients complaining of severe chronic periodontitis, with a minimum probing depth (PD) of $5 \mathrm{~mm}$ or more. All involved Pts. signed a free informed consent form. The subjects went through a complete clinical evaluation and received radiographic and periodontal examination. At the initial treatment, all subjects received Oral Hygiene Instruction (OHI) and supra- and sub-gingival ultrasonic scaling of all teeth. CG had used same procedure, but without activation of DL. After microbial specimens had been collected with sterile paper tips, and measuring of the clinical parameters; the experimental teeth selected for comparable treatment were subjected to scaling. One week after scaling, Pts. underwent DL treatment for 3sessions one week apart for three consecutive sessions for SG, while CG received saline irrigation only, and another microbial series were taken before each session, which evaluated to verify microbial elimination from the periodontal pockets of both groups.

Measurement of clinical dental parameters: The first clinical parameter were included: Pocket Depth (PD), followed by Plaque Index (PI), and Bleeding on Probing (BOP).

Periodontal pocket assessment: Six sites per tooth were measured with a Periodontal Probe (Hu-Friedy ${ }^{\circledR}$ Co.) and the deepest site of each study tooth was defined as the experimental site. All measurements were carried out by the same examiner to create comparable conditions; Pts. were asked to brush their teeth twice daily after meals with specific tooth paste (Aloe dent) and were instructed in proper oral hygiene measures. Furthermore, all Pts. underwent scaling at the first appointment.

Plaque index assessment: The PI as developed assesses the thickness of plaque at the cervical margin of the tooth (closest to the gum). Four areas, distal, labial or buccal, mesial, and lingual or palatal, were examined. Each tooth was dried and examined visually using a mirror, and an explorer, and adequate light. The explorer was passed over the cervical third to test for the presence of plaque. Four different scores are possible. Zero indicates no plaque present; 1 indicates a film of plaque present on the tooth; 2 represents moderate accumulation of soft deposits in the gingival pocket or on the tooth that can be seen by the naked eye; 3represents an abundance of soft matter within the pocket or on the tooth. Each area of each tooth is assigned a score from (0-3) Scores for each tooth were totaled and divided by the four surfaces scored. To determine a total PI for an individual, the scores for each tooth are totaled and divided by the number of teeth examined. Four ratings may then be assigned: $0=$ excellent, $0.1-0.9=$ good, $1.0-1.9=$ fair, $2.0-3.0=$ poor

Bleeding on Probing (BOP): An early sign of gingivitis is bleeding on probing and described it as the Sulcus Bleeding Index (SBI). The criteria for scoring are as follows: Score 0: healthy looking papillary and marginal gingiva no bleeding on probing. Score 1: healthy looking gingiva, bleeding on probing. Score 2: bleeding on 
probing, change in color, no edema, Score 3: bleeding on probing, change in color, slight edema. Score 4: bleeding on probing, change in color, obvious edema. Score5: spontaneous bleeding, change in color, marked edema. Four gingival units are scored systematically for each tooth: the labial and lingual marginal gingival (M units) and the mesial and distal papillary gingival (P units). Scores for these units are added and divided by four. Adding the scores of the undivided teeth and dividing them by the number of teeth can determine the sulcus bleeding index, of course, the pocket anatomy must be visualized along with amounts of debris and inflammation present in determining the time needed to adequately treat the site. The appointment protocol follows a simple formula, suggested for a one-hour appointment time ${ }^{[31]}$. The tooth and root surface (the hard side of the pocket) are debrided first, followed by laser bacterial reduction and coagulation of the soft side (epithelial tissue) of the sulcus. It's important to note that the laser parameters are adjusted to much lower settings than would be used for conventional surgery, remembering that the tissue temperature only needs to be elevated to 60 degrees $\mathrm{C}$. Therapy always began in the area with the deepest pocket depths and progress to the more shallow ones. On subsequent appointments, the clinician re-lased the previously treated sites.

Soft tissue DL treatment: Following scaling, Diode Laser equipment (Discus Soft Laser Pro, LLC of ZAP Lasers, Culver City, CA90232 USA) with a wave length of $808 \pm 5 \mathrm{~nm}$, delivered by a400- $\mu \mathrm{m}$ diameter fiber optic device was used for this trial. After tooth debridement, and coronal polishing of both teeth, the fiber optic was introduced in the periodontal pocket parallel to the long axis of the tooth, one millimeter coronal to the base of the pocket, and it was moved coronal with sweeping movements, using a power of $1.5 \mathrm{~W}, 20 \mathrm{~s}$ and power of density of $1,193.7 \mathrm{~W} / \mathrm{cm}^{2}$. Each pocket was probed to recheck the architecture and reconfirm the depth. The probe is then placed next to the Laser fiber assembly and the fiber length is adjusted in length. The calibration depth is $1 \mathrm{~mm}$ shorter than the pocket. This measurement is important because the Laser energy will penetrate through the tissue and the adjustment will minimize any interaction with the epithelial attachment, calibration of Laser fiber $1 \mathrm{~mm}$ less than pocket depth. At subsequent therapy appointments the fiber calibration is $2 \mathrm{~mm}$ less than the initial.

\section{Microbial pattern:}

-Microbial sampling: Patients were recalled at 2weeks, 4weeks, 6weeks and 10weeks after (SRP+ SRP+L) for microbiologic sampling, sub gingival plaque collection, the teeth were isolated with cotton rolls and a plaque sample was obtained by the introduction of two sterile no. 40 paper cones inside the pocket for $20 \mathrm{~s}$. Plaque samples were collected at baseline, and at each recall visit. The samples were placed in a vial containing $3 \mathrm{ml}$ transport medium (VMGA III)

-Microbial methods: Specimens were processed up to $24 \mathrm{hrs}$. after collection. The vials containing the cones in the VMGA III were incubated at $37^{\circ} \mathrm{C}$ for 30 min to liquefy the jelly, and then they were immediately homogenized in tube agitators (FisherVortex Genie 2, USA). Aliquots of $100 \mu 1$ from each sample, some diluted to 1/10 and 1/ 100 in peptone water, were put into Petri dishes containing a TSBV-selective culture medium (Tryptic soy agar added to horse serum, Bacitracin and Vancomycin) ${ }^{[33]}$. Cultures were reading within 2448hrs., of incubation at $37^{\circ} \mathrm{C}$.

Data Analysis: The data were recorded and entered into Microsoft excel sheet, then summarized and analyzed

\section{Results}

Table1 and figure1\&2: Prevalence of clinical dental indices during study phases

\begin{tabular}{|c|c|c|c|c|c|c|c|}
\hline \multirow{2}{*}{\multicolumn{2}{|c|}{ Dental clinic appointment }} & \multicolumn{6}{|c|}{ Teeth indices } \\
\hline & & \multicolumn{3}{|c|}{$\begin{array}{c}\text { Study group }(\mathbf{S G}) \\
* \text { No.=35*Pts. }\end{array}$} & \multicolumn{3}{|c|}{$\begin{array}{c}\text { Control group (CG) } \\
\text { *No.= 15*Pts. }\end{array}$} \\
\hline Phases & Appointment & *PD & $* \mathbf{P I}$ & $*^{*} \mathrm{BOP}$ & *PD & $* \mathbf{P I}$ & ${ }^{*} \mathbf{B O P}$ \\
\hline $\begin{array}{l}\text { Phase 1: } \\
\text { Baseline }\end{array}$ & $\begin{array}{l}1^{\text {st }} \text { visit } \\
\text { At } 1^{\text {st }} \text { week }\end{array}$ & 6.8 & 2.85 & $97.8 \%$ & 6.35 & 2.65 & $95.3 \%$ \\
\hline \multirow{3}{*}{$\begin{array}{l}\text { Phase 2: } \\
\text { Treatment } \\
\text { secessions }\end{array}$} & $\begin{array}{l}2^{\text {nd }} \text { visit } \\
\text { At } 2^{\text {nd }} \text { week }\end{array}$ & 5.5 & 1.67 & $64.2 \%$ & 5.7 & 1.85 & $83.8 \%$ \\
\hline & $\begin{array}{l}3^{\text {rd }} \text { visit } \\
\text { At } 4^{\text {th }} \text { week }\end{array}$ & 4.45 & 1.22 & $37.7 \%$ & 4.8 & 1.15 & $80.6 \%$ \\
\hline & $\begin{array}{l}4^{\text {th }} \text { visit } \\
\text { At } 6^{\text {th }} \text { week }\end{array}$ & 4.0 & 0.75 & $15.2 \%$ & 4.0 & 0.95 & $78.2 \%$ \\
\hline $\begin{array}{l}\text { Phase 3: } \\
\text { Follow up }\end{array}$ & $\begin{array}{l}5^{\text {th }} \text { visit } \\
\text { At } 10^{\text {th }} \text { week }\end{array}$ & 3.1 & 0.50 & $0.9 \%$ & 3.1 & 0.75 & $\mathbf{7 4 . 8 \%}$ \\
\hline
\end{tabular}



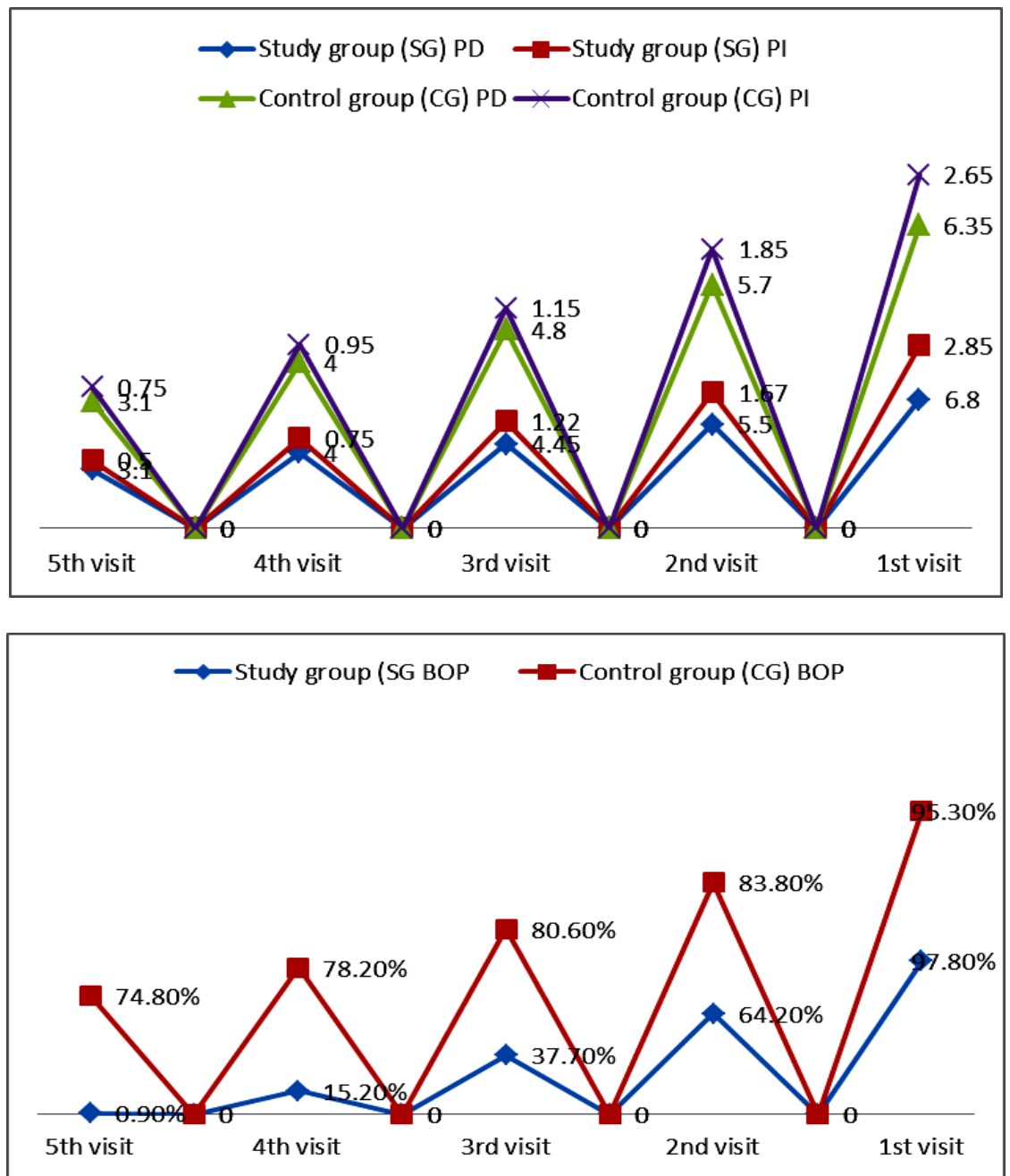

Clinical dental parameters: There was a significant $(\mathrm{p}<0.001)$ reduction in PD in test $(3.70 \mathrm{~mm})$ and control groups $(3.25 \mathrm{~mm})$. As regards PI, there was a significant reduction of $2.35 \mathrm{in}$ the test group and 1.90in the control groups. BOP (test 96.9\%): control: 20.5\%) presented significant reduction in BOP. There was no difference between groups in any of the experimental times (Table 1). There was a significant improvement of the studied clinical parameters, Probing Depth (PD), Plaque Index (PI) and Bleeding on Probing (BOP) for both groups $(\mathrm{P}<0.001)$, with statistical difference between them at 4 weeks, and8weeks examinations.

Table2 and figure 3 : Prevalence of the mean bacterial *CFUs/ml during study phases

\begin{tabular}{|c|c|c|c|c|c|c|c|}
\hline \multirow{2}{*}{\multicolumn{2}{|c|}{ Microbial scan }} & \multicolumn{6}{|c|}{ *CFUs/ml } \\
\hline & & \multicolumn{3}{|c|}{$\begin{array}{c}\text { Study group }(\mathrm{SG}) \\
* \text { No. }=35 * \text { Pts }\end{array}$} & \multicolumn{3}{|c|}{$\begin{array}{c}\text { Control group }(\mathrm{CG}) \\
* \text { No. }=15 * \mathrm{Pts}\end{array}$} \\
\hline Phases & Appointment & Aerobic & Anaerobic & Total & Aerobic & Anaerobic & Total \\
\hline $\begin{array}{l}\text { Phase 1: } \\
\text { Baseline }\end{array}$ & $\begin{array}{l}1^{\text {st }} \text { visit } \\
\text { At } 1^{\text {st }} \text { week }\end{array}$ & 300 & 100 & 400 & 300 & 110 & 410 \\
\hline \multirow{3}{*}{$\begin{array}{l}\text { Phase 2: } \\
\text { Treatment } \\
\text { secessions }\end{array}$} & $\begin{array}{l}2^{\text {nd }} \text { visit } \\
\text { At } 2^{\text {nd }} \text { week }\end{array}$ & 240 & 80 & 320 & 260 & 90 & 350 \\
\hline & $\begin{array}{l}3^{\text {rd }} \text { visit } \\
\text { At } 4^{\text {th }} \text { week }\end{array}$ & 200 & 50 & 250 & 230 & 70 & 300 \\
\hline & $\begin{array}{l}4^{\text {th }} \text { visit } \\
\text { At } 6^{\text {th }} \text { week }\end{array}$ & 140 & 30 & 170 & 200 & 60 & 260 \\
\hline $\begin{array}{l}\text { Phase 3: } \\
\text { Follow up }\end{array}$ & $\begin{array}{l}5^{\text {th }} \text { visit } \\
\text { At } 10^{\text {th }} \text { week }\end{array}$ & 80 & 10 & 90 & 140 & 50 & 190 \\
\hline
\end{tabular}

*CFUs: Colony Forming Units, *No.: Number, *Pts: patients 


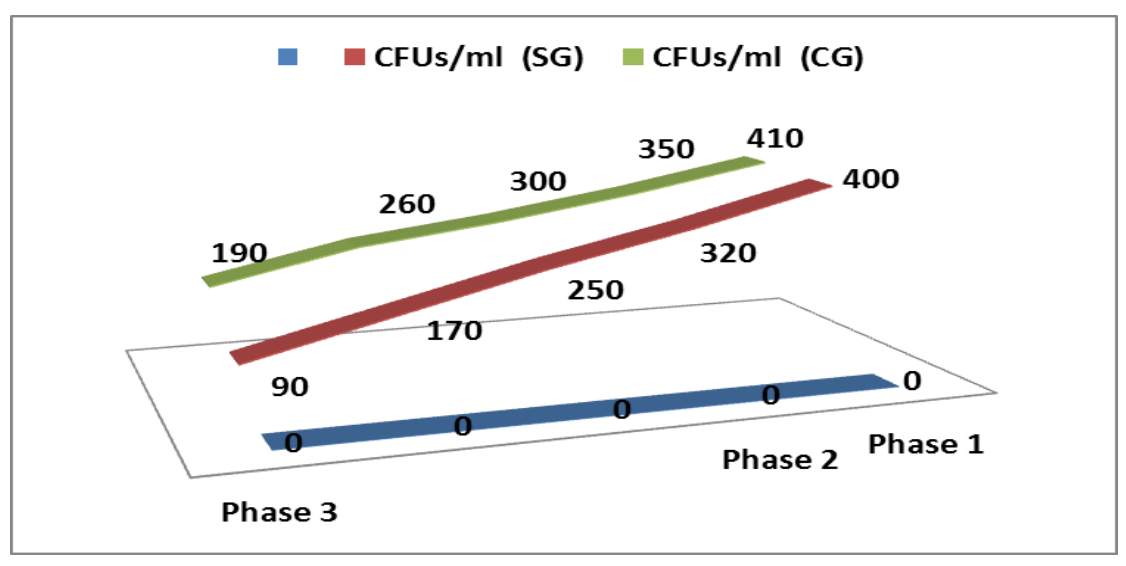

Table 2 and figure 3 show prevalence of the mean bacterial CFUs $/ \mathrm{ml}$ during study phases, that revealed $(400,320,250,170$ and 90) and (410, 350, 300, 260 and 190) CFUs/ml from SG and CG respectively. As for microbiological analysis, a significant reduction after 4 and 8 weeks was observed as far as CFUs $/ \mathrm{ml}$ is concerned, for both groups. As for black-pigmented bacteria, a significant reduction was observed in both groups after 8 weeks. However, the difference between test and control groups was not significant. There was no association between groups and presence of Porphyromonas gingivalis, Prevotella intermedia and Aggregatibacter Actinomycete mcomitans at any time of the study.

\section{Discussion}

Due to its characteristics, as well to other known advantages such as low cost and practicality, DL has been compared to the other Lasers, and has been subject to a diversity of studies intended to evaluate its potential in relation to its biocompatibility and to its ability in reducing bacterial counts ' Results have been controversial, many of which have stated that they did not find any additional benefits by using DL during nonsurgical periodontal treatment. However, other studies have shown positive results both clinically as well as microbiologically using the same type of Laser. The variability of results most probably related to the diversity of methods utilized a high potency $(2.5 \mathrm{~W})$ was used which is no longer rendered safe and may cause damage such as fusion, carbonization and necrosis, as well as excessive heating of the root surface. The goals of this randomized clinical trial were to verify, by means of bacterial reduction and changes in clinical parameters, the efficacy of the high-intensity DL as an adjunct to scaling and root planning (SRP), by using previously in vitro tested parameters. The choice of high-intensity DL was supported in the previous in vitro studies. Our primary interest was that laser could be effective and also safe. So in order to set these parameters that demonstrated that high intensity DL ( $1.4 \mathrm{~W} / 30 \mathrm{~s})$ did not cause any signs of thermal effects such as charring, necrosis or fusion on the root which inferred about the angle of Laser beam, time and power irradiation on gingival fibroblasts. Other characteristics about this Laser were taken into account in order to use in dental practice: it is one of the cheaper high intensity Laser; furthermore DL machine used in this research is small and light, therefore portable Lasers, as a group, have inconsistently demonstrated the ability to reduce microorganisms within a periodontal pocket ${ }^{[13-14]}$. Nonsurgical mechanical therapy alone may not effectively eliminate the periodontal disease completely, particularly in deep pockets. Hence, surgical therapy is performed, which provides improved visualization of the root surface and defects. Soft tissue Lasers such as DL and Nd:YAG have the potential for curettage of pocket wall and disinfection of periodontal pockets. Er:YAG laser can be used for both soft and hard tissue debridement. There are no reports of the use of DL as an adjunct to mechanical debridement in access flap surgery, although it is the most commonly used Laser. The adjunctive effects of DL in open flap debridement have been evaluated based on clinical and microbiological parameters. In the present study, PI was used to monitor the oral hygiene status of patients. The results demonstrated that there was a statistically significant difference in PI at baseline and at 2 months in the control and the test groups. PI score became $<1$ at the $4^{\text {th }}$ week post-operatively after the second lasing session suggesting maintenance of fair oral hygiene by the patients throughout the study. On the other hand, BOP decreased significantly from baseline to 8 weeks in the test group rather than the control group. This suggests the effectiveness of mechanical SRP+ laser radiation in reducing signs of inflammation due to the effective removal of calculus and infected granulation tissue . The reduction of pocket depth was significantly greater in the Laser group at $4-8$ weeks after lasing. Each Laser has a different property and different tissue interactions, which depend upon the wavelength, power, waveform, tissue optical properties and tissue thermal properties. DL is an excellent soft tissue and available in smaller cost-effective units. The radiation of DL shows greater absorption and less penetration than does Nd:YAG Laser, especially in blood-rich tissue. Therefore, collateral damage with DL is less than with Nd:YAG or $\mathrm{CO}_{2}$ Laser. The wavelength of DL is absorbed by the hemoglobin, which leads to tissue coagulation and formation of charred 
layer. DL leads to thermo coagulation of blood vessels, which is responsible for its hemostatic effect. Thus, DL is an excellent soft tissue laser because of its tissue coagulating and hemostatic properties. DL mode of antisepsis has several potential advantages over traditional biochemical antibiotics. A therapeutic dose can be delivered to a greater depth locally and leaves no residual concentration .Laser radiation affects equally extracellular and intracellular pigmented pathogens ${ }^{[45]}$. Laser energy has the potential to breach the protective mechanisms of biofilms. In the present study, there was a statistically significant reduction in the number of CFUs of anaerobes in DL SG compared with CG. The wave length of DL was absorbed by protohemin and protoporphyrin IX pigments of the pigmented anaerobic peri pathogens. This led to vaporization of water and caused lysis of the cell wall of the bacteria, leading to cell death. It was effective against the tissue invasive peri pathogens caused by absorption of Laser energy up to1-2mm in the deeper tissues. It has been hypothesized that the charred layer that forms on the undersurface of the flap prevents the epithelial migration and promotes new attachment. Provided histological evidence of formation of new cement, periodontal ligament, and bone. When $\mathrm{CO}_{2}$ Laser was used for debridementing class III furcation defects used Er:YAG Laser for debridement during access flap surgery and noted promoted more new bone formation. The bactericidal effect of DL is evident from the reduction in the CFUs of obligate anaerobes. DL irradiation also is anti-microbial in tissues because of deeper penetration of laser energy. The possible role of DL in anti-microbial and promoting formation of new attachment. If the possibility of selective eradication of bacteria by DL is considered, those making such claims must also consider that periodontitis is a mixed infection involving at least 30 or more microbial spp. Many spp. of oral bacteria that formally belonged to the genus Bacteriods, Porphyromonas, Prevotella, Tannerella, and Bacteriods still exists. Porphyromonas gingivalis need not be present in large numbers to dictate disease initiation or progression. Porphyromonas gingivalis as a "keystone" member of the sub gingival microbial biofilm. The "keystone" designation indicates that while this microbe resides in low numbers within the periodontal pocket it still has the ability to dictate host immune cell response. Further, it must be considered that, collectively, microbes of the genus Porphyromonas, Prevotella, and Bacteriods constitute less than $20 \%$ of the total sub gingival microbial flora. If the possibility of selective eradication of bacteria by DL is considered, it must be put into consideration that periodontitis is a mixed infection involving a plethora of microbial spp. Sub gingival Laser therapy, that relatively low numbers of highly pathogenic microbes, e g, Porphyromonas gingivalis, make it difficult to totally eradicate. Yet marketing statements continue to be made regarding "pocket sterilization" and assertions that DL and Laser wave lengths selectively destroy if the possibility of selective eradication of bacteria by DL is considered, those making such claims must also consider that periodontitis is a mixed infection involving at least 30 or more microbial spp. How the wavelength of the various DLs are related to selective destruction of black/brown-pigment-producing bacteria. This frequently stated concept caused, this paper was done to re-examine DL periodontal therapy conundrum. Consequently, the present work views on two issues both basic to DL periodontal therapy, benefit of DL sub gingival curettage, and reduction of microbial counts found in the periodontal pockets

\section{Conclusions}

Diode Laser was well tolerated by the patients and it demonstrated a significant bactericidal effect. Therefore, Lasers can form an integral part of periodontal therapy in the future. However, further longitudinal studies are required to evaluate the long-term effects of Diode Laser on clinical as well as microbiological parameters. The bactericidal effect of Diode Laser on specific microorganisms and time taken for microbial recolonization needs to be determined by further studies. Further studies are required to provide an insight into the healing and a possible role for Diode Laser in the formation of new attachment. After 2 months of evaluation, Diode Laser has shown additional benefits to the conventional periodontal treatment. Clinical relevance due to the high intensity Diode Laser provided additional benefits to non-surgical periodontal treatment. More studies are necessary to prove the actual need of this type of Laser in the periodontal clinical practice. A comparison between the initial and the final bacterial CFUs revealed that irradiation with Diode Laser facilitates considerable bacterial elimination, especially of Actino bacillus Actinomycete mcomitans, from periodontal pocket.

\section{References}

[1]. Akoi, M., 2008. Current status of clinical laser applications in periodontal therapy, General Dentistry, PP: 674-687.

[2]. Moritz, G., 1997. Bacterial reduction in periodontal pockets through irradiation with a diode laser: a pilot study, J. Cline. Laser Med Surg., 15: 33-37.

[3]. Harris, Y., 2004. Therapeutic ratio quantifies laser antisepsis: Ablation of Porphyromon as gingivalis with dental lasers, Lasers Surg. Med., 35: 206-213.

[4]. Ciancio, C., 2006. Wound healing of periodontal pockets using the diode laser, Applications of 810nm Diode Laser Technology: A Clinical Forum,: 14-17.

[5]. Fontana, K., 2004. Microbial reduction in periodontal pockets under exposition of a medium power diode laser: an experimental study in rats, Lasers Surg. Med., 35(4):263-268.

[6]. Andreanna, A., 2004. The use of diode lasers in periodontal therapy, Dentistry Today, November, 24: 11-21. 
[7]. Ciancio, C., 2006. Effect of a diode laser on Actino bacillus Actinomycete mcomitans, Biological Therapies in Dentistry, 22: 233239.

[8]. Haraszthy, Z., 2000. Identification of periodontal pathogens in athermanous plaques. J. Periodontal, 71: 1554-1560.

[9]. Spahr, K., 2006. Periodontal infections and coronary heart disease: role of periodontal bacteria and importance of total pathogen burden in the Coronary Event and Periodontal Disease (Corodont) study, Arch Intern Med., 166: 554-559.

[10]. Ishikawa, I., Aoki, A., Aristeo, A., Takasaki, Mizutani K., SasakiK, M. and Izumi, Y., 2009. Application of lasers in periodontics: true innovation or myth? Periodontal, 50: 90-126.

[11]. Pick, C., 1993. Current status of lasers in soft tissue dental surgery, J. Periodontal, 64: 589-602.

[12]. Gold, V., 1994. Pulsed laser beam effects on gingival. J. Clini. Periodontal, 21: 391-393.

[13]. Euzebio, V., Andrade, A., Toaliar, M., Conde, M., Zezell, M., CaiS, P. and Micheli, G., 2012. Clinical and microbiological evaluation of high intensity diode laser adjutant to non-surgical periodontal treatment: a 6-month clinical trial .Clin Oral InvestDOI..

[14]. Gokhale, S., Padhye, A., Byakod, G., Jain, S., Padbidri, V. and Shivaswamy, S., 2012. A Comparative Evaluation of the Efficacy of Diode Laser as an Adjunct to Mechanical Debridement Versus Conventional Mechanical Debridement in Periodontal Flap Surgery:A Clinical and Microbiological Study. Photomedicine and Laser Surgery,30: 598-603.

[15]. Flemming, T., 1999. Periodontitis. Ann. Periodontol. 4: 1-6.

[16]. Marsh, P., 1991. Sugar, fluoride, $\mathrm{pH}$ and microbial homeostasis in dental plaque. Proc. Finn. Dent. Soc. 87: 515-525..

[17]. Haffajee, A. and Socransky, S., 1994. Microbial etiological agents of destructive periodontal diseases. Periodontal. 5: 78-111.

[18]. Darveau, R.., Tanner, A. and Page, R., 1997. The microbial challenge in periodontitis. Periodontol. 14: 12-32.

[19]. Page, R., Offenbacher, S., Schroeder, B., Seymour, G. and Kornman, K., 1997. Advances in the pathogenesis of periodontitis: Summary of developments, clinical implications and future directions, Periodontal. 14: 216-248.

[20]. Schenk, G., Flemmig, T., Lob, S., Ruckdeschel, G. and Hickel, R., 2000. Lack of antimicrobial effect on periodontopathic bacteria by ultrasonic and sonic scalers in vitro. J. Cline. Periodontal. 27: 116-119.

[21]. Ishikawa, I., and Baehni, P. (2004). Nonsurgical periodontal therapy - where do we stand now? Periodontol. 2000. 36, 9-13.

[22]. Aoki, A., Sasaki, K.M., Watanabe, H., and Ishikawa, I. (2004). Lasers in non-surgical periodontal therapy.Periodontol.2000. 36, 997.

[23]. Adriaens, P.A., Edwards, C.A., De Boever, J.A., and Loesche, W.J. (1988). Ultrastructural observations on bacterial invasionincementum and radicular dentin of periodontallydiseased human teeth. J. Periodontol. 59, 493-503..

[24]. Shimizu, N., Yamaguchi, H., Goseki, T., Shibata, Y., Takiguchi, H., Iwasawa, T., and Abiko, Y. (1995). Inhibition of prostaglandin E2 and interleukin $1 \mathrm{~b}$ production by low-power laser irradiation in stretched human periodontal ligament cells. J. Dent. Res. 74 , 1382-1388.

[25]. Quadri, T., Miranda, L., Tuner, J., and Gustafsson, A. (2005). The short term effects of low level lasers as adjunct therapy in treatment of periodontal inflammation. J. Clin. Periodontol.32, 714-719.

[26]. Shimotoyodome, A., Okajima, M., Kobayashi, H., Tokimitsu, I., and Fujimura, A. (2001). Improvement of macromolecular clearance via lymph flow in hamster gingiva by low-power carbon dioxide laser-irradiation.Lasers Surg. Med. 29, $442-4$.

[27]. Yilmaz, S., Kuru, B., Kuru, L., Noyan, U., Argun, D., and Kadir, T. (2002). Effect of gallium arsenide diode laser on human periodontal disease: a microbiological and clinical study. Lasers Surg. Med. 30, 60-66

[28]. Silness, J., and Loe, H. Periodontal disease in pregnancy. II. (1964). Correlation between oral hygiene and periodontal condition.ActaOdontol. Scand. 22, 121-135.

[29]. Loe, H., and Silness, J. Periodontal disease in pregnancy. I. (1963).Prevalence and severity.ActaOdontol.Scand.21,533-551.

[30]. Muhlemann, H.R.; Son, S. Gingival sulcus bleeding - a leading symptom in initial gingivitis. Helvetica OdontologicaActa, 15,. 2 (1971),107-113.

[31]. Moritz, A., Schoop, U.,Goharkhay, K., and Schauer, P. (1998). Treatment of periodontal pockets with a diode laser.Lasers Surg. Med. 22, 302-311.

[32]. Asikainen S, Chen C, Slots J (1995) Actinobacillus-actinomycetemcomitansgenotypes in relation to serotypes and periodontalstatus. Oral MicrobiolImmunol 10:65-68.

[33]. Roman-Torres CVG, Aquino DR, Cortelli SC et al (2010) Prevalence and distribution of serotype-specific genotypes of Aggregatibacteractinomycetemcomitansin chronic periodontitis Brazilian subjects. Arch Oral Biol 55:242-248.

[34]. 34.Coulombier D, Fagan R, Hathcock L and Smith C (2001). Epi Info 6 Version 6.04.A Word Processing, Database and Statistical Program for Public Health.Centers for Disease Control and Prevention, Atlanta, Delaware, USA.

[35]. 35.Caruso U, Nastri L, Piccolomini R, D’Ercole S, Mazza C, Guida L(2008) Use of diode laser $980 \mathrm{~nm}$ as adjunctive therapy in thetreatment of chronic periodontitis. A randomized controlled clinicaltrial. New Microbiol 31:513-518.

[36]. De Micheli G, Andrade AKP, Alves VT, Seto M, Pannuti CM, CaiS (2011) Efficacy of a high intensity diode laser as an adjunct tonon-surgical periodontal treatment: a randomized controlled trial Laser Med Sci 26:43-48.

[37]. Kerry, G. (1994). Tetracycline-loaded fibers as adjunctive treatment in periodontal disease. J. Am. Dent. Assoc. 12, $1199-1203$.

[38]. Theodoro LH, Haypek P, Bachmann L et al (2003) Effect of Er:YAG and diode laser irradiation on the root surface: morphologicaland thermal analysis. J Periodontol 74:838-843

[39]. Haypek P, Zezell DM, Bachmann L, Marques MM (2006) Interactionbetween high-power diode laser and dental root surface.Thermal, morphological and biocompatibility analysis. J Oral LaserAppl 6:1-9.

[40]. Kreisler M, Daublander M, Willershausen-Zonnchen B, D'HoedtB (2001) Effect of diode laser irradiation on the survival rate ofgingival fibroblast cell cultures. Laser Surg Med 28:445-450.

[41]. Kreisler M, Al Haj H, D’Hoedt B (2005) Clinical efficacy ofsemiconductor laser application as an adjunct to conventionalscaling and root planing. Laser Surg Med 37:350-355

[42]. Ribeiro, I.G.J., Sbrana, M.C., Esper, L.A., and Almeida, A. (2008). Evaluation of the effect of the GaAlAs laser on subgingivalscaling and root planing.Photomed. Laser Surg. 26, 387-391.

[43]. Lindhe, J., and Nyman, S. (1985). Scaling and granulationtissue removal in periodontal therapy. J. Clin. Periodontol.12, 374-388.

[44]. Chow, R., Armati, P., Laakso, E.L., Bjordal, J., and Baxter, G.D. (2011). Inhibitory effects of laser irradiation on peripheral mammalian nerves and relevance to analgesic effects: a systematic review. Photomed. Laser Surg. 29, 365-381.

[45]. 45. Centty, I.G., Blank, L.W., Levy, B.A., Romberg, E., and Barnes, D.M. (1996). Carbon dioxide laser for de-epithelialization of periodontal flaps. J. Periodontol. 68, 763-769.

[46]. 46. Gaspirc, B., and Skaleric, U. (2007). Clinical evaluation of periodontal surgical treatment with an Er:YAG laser: 5-year results. J. Periodontol. 78, 1864-1871.

[47]. Castro, G.L., Gallas, M., Nunez, I., LeyesBorrajo, J.L., and Garciavarcla, L. (2006). Histological evaluation of the use of diode laser as an adjunct to traditional periodontal treatment.Photomed. Laser Surg. 24, 64-68. 
[48]. Crespi, R., Covani, U., Margarone, J.E., and Andreana, S. (1997). Periodontal tissue regeneration in beagle dogs after laser therapy.Lasers Surg. Med. 21, 395-402.

[49]. Mizutani, K., Aoki, A., Takasaki, A., Kinoshita, A., Hayashi, C., Oda, S., and Ishikawa, I. (2006). Periodontal tissue healing following flap surgery using an Er:YAG laser in dogs. Lasers Surg. Med. 38, 314-324.

[50]. Contreras, A., and Slots, J. (1996). Mammalian viruses in human periodontitis.OralMicrobiol.Immunol. 5, $289-293$.

[51]. Saygun, I., Sahin, S., O” zdemir, A., Kurtis, B., Yapar, M., Kubar, A., and Ozcan, G. (2002).Detection of human viruses in patients with chronic periodontitis and the relationship between viruses and clinical parameters. J. Periodontol. 73, 1437-1443.

[52]. Mayrand D, Holt SC. (1988) Biology of asaccharolytic black-pigmented Bacteroides species. Microbiol Rev.52:134-152.

[53]. Socransky SS, Haffajee AD, Cugini MA, et al.(1998) Microbial complexes in sub gingival plaque. JClin Periodontol.25:134-144

[54]. Loomer PM, Armitage G C. (2004) Microbiology of periodontal diseases. In: Rose LF, Mealey BL, Genco RJ, Cohen DW, eds. Periodontics: Medicine, Surgery and Implants. St. Louis, MO: Mosby; 75.

[55]. Paster BJ, Olsen I, Aas JA, Dewhirst FE. (2006) The breadth of bacterial diversity in the human periodontal pocket and other oral sites.Periodontol 2000. 42: 80-87.

[56]. Christopher H, Blackburn P (2011) Text Book of laser physics RDH, 31:66-72. 